\title{
Caracterização dos canais de comercialização do vinho no Alentejo: uma abordagem com base na teoria dos custos de transação
}

\author{
Characterization of Wine Marketing Channels in Alentejo: An approach \\ based on the theory of transaction costs
}

\author{
Ana Rebocho' (1), Rui Fragoso² (1) \\ ${ }^{1}$ Universidade de Évora, Évora, Portugal. E-mail: anarebocho18@gmail.com \\ ${ }^{2}$ Centro de Estudos e Formação Avançada em Gestão e Economia (CEFAGE), Universidade de Évora, Évora, Portugal. E-mail: \\ rfragoso@uevora.pt
}

\begin{abstract}
Como citar: Rebocho, A., \& Fragoso, R. (2021). Caracterização dos canais de comercialização do vinho no Alentejo: uma abordagem com base na teoria dos custos de transação. Revista de Economia e Sociologia Rural, 59(1), e238881.
\end{abstract} https://doi.org/10.1590/1806-9479.2021.238881.

\begin{abstract}
Resumo: O setor do vinho em Portugal tem-se afirmado com produtos genuinamente únicos que têm ganho reputação nos mercados. O potencial de diferenciação e a reduzida dimensão do mercado nacional para absorver a produção têm levado a uma estratégia de consolidação no mercado externo, sendo importante uma gestão eficiente dos canais de comercialização. Assim, este estudo visa caracterizar a estrutura dos canais de comercialização das empresas do setor do vinho no Alentejo e avaliar o seu nível de integração, ou seja, pretende-se determinar como as restrições verticais influenciam a eficiência das transações nesses canais de comercialização. A metodologia utilizada seguiu uma abordagem mista, baseada na realização de entrevistas (reuniões) com especialistas do setor e na elaboração de um questionário a ser aplicado em uma amostra de empresários do setor do vinho no Alentejo. Os resultados obtidos indicam que as empresas utilizam vários tipos de canais de comercialização para a exportação. Ao contrário do que é referido na literatura, as empresas objeto de estudo, geralmente, não coordenam as suas transações por meio de contratos. Os resultados permitiram, ainda, concluir que a incerteza afeta os custos de transação, bem como os ativos específicos, nomeadamente associados aos recursos humanos. Verificou-se também que quanto maior a frequência das transações, maior o nível de integração dos canais de comercialização.
\end{abstract}

Palavras-chave: canais de comercialização, teoria dos custos de transação, setor do vinho.

\begin{abstract}
In Portugal, the wine industry has been successful in the last years with genuine products, which have gained a reputation in domestic and foreign markets. The potential of differentiation and the reduced size of the domestic market have lead consolidate positions in foreign markets, where efficient management of the marketing channels is important. Thus, this study has as objective the characterization of the marketing channels structures in the wine industry of Alentejo, and the assessment of their level of integration. In other words, it was aimed to know how the vertical constraints influence the transaction efficiency in those marketing channels. The methodology used was a mixed approach based on quantitative and qualitative analyzes. The former was based on interviews with wine industry's experts, and the latter was carried out through a questionnaire applied to a sample of wine entrepreneurs from Alentejo. The results showed that the wine companies use several marketing channels for exports. By contrast to the literature, the analyzed companies do not coordinate their transactions through contracts. The results also allowed to conclude that uncertainty affects the transaction costs, as well as, asset specificity and namely those associated with human resources. Another conclusion is that the greater the frequency of transactions, the greater the level of integration of the marketing channels of the wine industry.
\end{abstract}

Keywords: marketing channels, theory of transaction costs, wine industry. 


\section{INTRODUÇÃO}

Em Portugal, o setor do vinho tem um forte impacto na economia nacional. Segundo o Instituto Nacional de Estatística (2016), o vinho foi o nono principal produto comercializado para mercados externos. De acordo com dados do Instituto da Vinha e do Vinho (2015), a produção de vinho, em 2015, foi de $6.206 \mathrm{mhl}$ e o consumo foi de $4.940 \mathrm{mhl}$. Além de os vinhos serem um dos principais bens exportados por Portugal, são também um dos produtos que registraram os maiores excedentes comerciais (Instituto Nacional de Estatística, 2016). Segundo a mesma fonte, o valor das exportações de vinhos tem aumentado continuadamente desde 2011. Apesar de as quantidades exportadas terem diminuído, o valor do vinho aumentou. Importa, ainda, salientar que os principais mercados de destino do vinho, em termos do valor total exportado, são França (14,9\%), Reino Unido (10,6\%), Angola (9,9\%) e Estados Unidos (9,3\%).

Esses números mostram a importância e a dinâmica do setor do vinho em Portugal e para o qual o país dispõe de fatores de competitividade relevantes. As condições naturais, nomeadamente o clima, os solos e a grande variedade de castas, permitem obter produtos genuinamente únicos. A elevada reputação, mesmo nos mercados externos, bem como a ligação ao setor do turismo, proporciona também um posicionamento diferenciado. 0 Alentejo é uma das maiores regiões vitivinícolas do país e os vinhos lá produzidos são reconhecidos como produtos de elevada qualidade. O potencial de diferenciação do vinho alentejano aliado à reduzida dimensão do mercado nacional para absorver a totalidade da produção leva a encarar a exportação como uma oportunidade estratégica. No entanto, particularidades dos processos de exportação mencionam o problema do nível de integração dos canais de comercialização e, por conseguinte, da eficiência das transações, que, neste estudo, encerram as seguintes questões de pesquisa:

i) Que canais de comercialização são utilizados nas empresas do setor do vinho no Alentejo na exportação dos seus produtos?

ii) Como as empresas do setor do vinho no Alentejo se relacionam com outros agentes nos canais de comercialização?

Na literatura, existem vários estudos que relacionam a teoria dos custos de transação com questões relacionadas aos canais de comercialização, nomeadamente custos de transação nos mercados internacionais (Klein et al., 1990) e a escolha dos canais que minimizam os custos de transação (Kabadayi, 2011). Neste estudo, pretende-se determinar o nível de integração dos canais de comercialização usados na exportação do vinho no Alentejo, tendo como base a teoria dos custos de transação, ou seja, pretende-se determinar como as restrições verticais influenciam a eficiência das transações nesses canais de comercialização.

Uma das razões da realização deste estudo prende-se à escassez da literatura na área de canais de comercialização de exportação no setor vinho no Alentejo. Deste modo, o estudo realiza a caracterização da estrutura dos canais de comercialização das empresas do setor do vinho no Alentejo, com base no seu nível de integração, à luz da teoria dos custos de transação. Portanto, pretende-se conhecer o nível de integração dos canais de comercialização e compreender as principais razões que influenciam a decisão, procurando, de um modo mais específico:

i) identificar os canais de comercialização utilizados pelas empresas na exportação do vinho e a forma como se relacionam com outros agentes nos canais;

ii) avaliar a influência que a especificidade dos ativos, a incerteza e a frequência das transações têm no nível de integração dos canais de comercialização.

Para caracterizar a estrutura dos canais de comercialização das empresas vitivinícolas do Alentejo, realizaram-se várias entrevistas com elementos da Comissão Vitivinícola Regional Alentejana (CVRA), além de um questionário que foi entregue a todos os produtores de vinho inscritos na base da CVRA, tendo em conta as características da empresa e do empresário/gestor, do processo de exportação e das transações (frequência, especificidade dos ativos e incerteza) e perspectivas para o futuro.

Para além desta introdução, este artigo está organizado em mais quatro seções. A primeira é relativa à revisão da literatura, em que se faz um enquadramento teórico dos 
canais de comercialização e da teoria dos custos de transação. A segunda seção é dedicada à metodologia utilizada e as últimas duas dizem respeito aos resultados e à conclusão.

\section{REVISÃO DA LITERATURA}

Segundo Corey et al. (1989), os canais de comercialização são redes de agentes por meio das quais os produtos fluem dos produtores até os consumidores finais. Para Kumar et al. (1995), os canais de comercialização são conjuntos de organizações que operam de forma interdependente para tornar os produtos e serviços dos produtores disponíveis aos consumidores finais. Pelton et al. (1997) definiram os canais de comercialização como relações de trocas que agregam valor ao produto. Rosembloon (1999) considera que os canais de comercialização são entidades externas que a empresa utiliza para atingir seus objetivos comerciais. Portanto, os canais de comercialização fazem chegar os produtos aos consumidores finais e são determinantes na criação de vantagens competitivas.

Nos canais de comercialização, os seus membros criam relações de dependência, mas desejam, acima de tudo, manter a autonomia (Rehme et al., 2016). Nessa perspectiva, é importante decidir quais funções de comercialização a empresa deve realizar e quais deve delegar ao mercado. Tradicionalmente, a decisão é baseada no argumento da minimização dos custos de produção e de comercialização (Stern \& El-Ansary, 1988). Esses custos são importantes do ponto de vista da eficiência, mas não explicam as diferentes estratégias de controle nem a utilização de diferentes níveis de integração dos canais.

A teoria dos custos de transação de Williamson $(1975,1985)$ dá uma nova perspectiva sobre as forças que moldam a estrutura do canal. Segundo Coase (1937), os custos de transação são aqueles envolvidos em uma troca de mercado entre duas empresas ou entre dois níveis de integração vertical na mesma empresa e em que se assume que a informação tem custos. Portanto, os custos de transação são os de governar o sistema (Klein et al., 1990) e podem ocorrer antes (custos ex-ante) ou depois (custos ex-post) da conclusão da transação. Os primeiros estão relacionados aos procedimentos necessários para realizar a transação (informação, negociação e redação de contratos). Os últimos são relativos aos mecanismos de controle necessários para verificar se as condições do acordo serão cumpridas.

No planejamento dos canais de comercialização, a teoria dos custos de transação ajuda as empresas a encontrar formas de governança mais eficientes de gerir as transações (Seggie, 2012). O objetivo é minimizar a soma dos custos de produção e dos custos de transação. Ao considerar que a empresa delega funções a agentes externos, admite-se a existência de custos de transação decorrentes de operações no mercado. Quanto mais elevados forem os custos para operar no mercado, maior será o incentivo à integração vertical dos canais (Fragoso, 2013).

A teoria dos custos de transação baseia-se nos pressupostos da racionalidade limitada e do oportunismo e tenta minimizar suas consequências mediante a escolha de formas mais eficientes de governança das transações.

O pressuposto da racionalidade limitada refere-se a comportamentos que pretendem ser racionais, mas não conseguem sê-lo completamente, dado que os agentes não conseguem processar toda a informação existente (Lopes, 2009). Desta forma, os contratos, mesmo os mais complexos e sofisticados, são sempre incompletos, o que pode criar condições para comportamentos oportunistas e a renegociação dos contratos.

O oportunismo ocorre quando os indivíduos agem com avidez em interesse próprio e tende a diminuir quando a eficiência da transação é maximizada (Jap \& Anderson, 2003). O oportunismo decorre da assimetria da informação, que pode levar a problemas de seleção adversa (adverse selection) e de risco moral (moral hazard) (Neves, 1990).

Seleção adversa ocorre quando uma das partes assume comportamentos oportunistas antes da elaboração do contrato, por ter acesso a informações privilegiadas ou exclusivas. $O$ tradicional exemplo do carro usado, de Akerlof (1970), ilustra bem essa situação. No problema de risco moral, um ou mais agentes envolvidos na transação adota(m) comportamentos oportunistas após a elaboração do contrato. Um exemplo paradigmático são os recursos humanos que trabalham inadequadamente sem supervisão. Outro exemplo são os fornecedores das indústrias alimentares que entregam produtos de qualidade inferior como 
se fossem produtos adequados. Nesses casos, o cliente tem de pagar pela simetria da informação para minimizar seus prejuízos, investindo em ações de inspeção e controle, e/ou oferecer incentivos para estimular comportamentos adequados.

Para Williamson (1981), a especificidade dos ativos, a incerteza e a frequência das transações são as três características das transações que determinam a existência de custos de transação.

A especificidade dos ativos é a característica mais importante na escolha das formas de governança das transações e relaciona-se ao fato de os investimentos físicos ou humanos necessários para realizar transações com um agente em particular terem um valor muito inferior em uma segunda alternativa de afetação (Kabadayi, 2011). Shervani et al. (2007) e Traversac et al. (2011) dão exemplos de possíveis ativos específicos, como terrenos, equipamentos técnicos, veículos de distribuição, armazéns, o conhecimento dos benefícios dos produtos pelos vendedores e as relações construídas ao longo do tempo. Seggie (2012) refere que quando se combina o oportunismo com a especificidade dos ativos, torna-se necessário analisar a transação com especial importância.

Segundo Williamson (1985) e Traversac et al. (2011), a incerteza é a segunda fonte de custos de transação. A incerteza torna a racionalidade limitada mais evidente, pois quanto maior for a incerteza, maior será a necessidade de adaptações no futuro e mais complexo será o contrato, de modo a acautelar a ocorrência de comportamentos oportunistas (Lopes, 2009; Seggie, 2012). Em um ambiente de incerteza, os agentes não conseguem prever os acontecimentos futuros e é maior a probabilidade de comportamentos oportunistas e de renegociação dos contratos.

A frequência refere-se ao número de vezes que as transações ocorrem com o mesmo parceiro, podendo classificar-se em recorrente ou ocasional (Williamson, 1985). Quando as transações são recorrentes, os agentes envolvidos tendem a desenvolver reputação, diminuindo atitudes oportunistas. Já quando são transações ocasionais, os agentes tendem a ter mais comportamentos oportunistas, uma vez que tentam retirar mais proveito da transação isolada, que possivelmente não se repetirá.

Williamson (1981) refere três formas básicas de governança: mercado à vista (spot), integração vertical e formas híbridas coordenadas por contratos. O mercado à vista normalmente implica mais custos de transação e é mais adequado a situações em que o preço é o elemento discriminatório, como é o caso das commodities (Peterson et al., 2001; Lopes, 2009). A integração vertical é a forma de governança que permite minimizar os custos de transação, sendo mais adequada a situações em que existam ativos específicos e as transações se processem em ambientes de elevada incerteza.

Entre o mercado à vista e a integração vertical, existe um conjunto de restrições verticais, designadas de formas híbridas, coordenadas por diversos tipos de contratos. Christy \& Grout (1994) apresentam como formas híbridas possíveis: estruturas divisionárias; subsidiárias detidas pela própria empresa; interesses no controlo; joint-ventures; licenciamentos e franquias; alianças estratégicas; contratos de longo prazo e de curto prazo.

São vários estudos na literatura dedicados ao setor do vinho que se inspiraram nos contributos de Williamson (1985) para a teoria dos custos de transação (Fraser, 2005; Fernández-Olmos et al., 2009; Fernández-Olmos, 2010; Codron et al., 2013; Miranda, 2016). No entanto, a maior parte desses estudos enfoca, principalmente, a influência dos custos de transação no aprovisionamento de uvas, a descrição dos trade-offs entre os contratos formais e os informais e as características contrastantes dos arranjos institucionais. Apesar da relevância desses estudos para o conhecimento das dinâmicas do setor do vinho, nenhum deles aborda, de forma explícita, os canais de comercialização do vinho. Deste modo, este estudo representa um contributo empírico original para a literatura no setor de vinho inspirados na teoria dos custos de transação.

\section{METODOLOGIA}

Tendo em conta os objetivos do estudo, foram formuladas as seguintes hipóteses à luz da teoria dos custos de transação de Williamson (1985): 
H1: Quanto maior for a especificidade dos ativos envolvidos numa transação, maior será o grau de integração vertical dos canais;

H2: Quanto maior for a frequência das transações entre os agentes, maior será o grau de integração vertical dos canais;

H3: Quanto maior for o grau de incerteza que envolve as transações, maior será o grau de integração vertical dos canais;

Para operacionalizar esse quadro teórico de análise, utilizou-se uma abordagem mista, em que, para compreender detalhadamente os canais de comercialização para os mercados externos das empresas vitivinícolas, foram realizadas várias entrevistas com membros da CVRA, bem como um questionário, que foi distribuído eletronicamente, pela ferramenta Google Forms, a uma amostra de empresas do setor do vinho no Alentejo.

A população do estudo é composta de empresas alentejanas produtoras de vinho inscritas na CVRA, ou seja, os produtores que produzem vinho certificado. Deste modo, foi selecionada uma amostra de 250 empresas que inclui todos os elementos que compõem a população. No entanto, apesar de todos os esforços, houve grande dificuldade no acesso aos dados, que se traduziu numa reduzida percentagem de respostas, visto que do universo de 250 empresas, apenas 20 responderam de forma cabal ao questionário.

O questionário utilizado é apresentado em anexo (ver Material Suplementar) e incluiu quatro grupos de questões que integram a operacionalização de 47 variáveis. Os grupos de questões considerados incluem: características da empresa e do empresário/gestor; características do processo de exportação; características das transações; perspectivas para o futuro.

O grupo características da empresa e do empresário/gestor conta com oito variáveis que fornecem informações sobre a dimensão e características da empresa, bem como informações pessoais e profissionais sobre o empresário/gestor responsável pela empresa.

Uma das variáveis medida nesse grupo de questões é se a empresa participa ou não de algum processo de exportação. $O$ interesse dessa variável relaciona-se ao objetivo de perceber a proporção de empresas do universo da CVRA que exportam seus produtos.

O grupo características do processo de exportação pretende caracterizar os arranjos institucionais que as empresas utilizam nos seus canais de comercialização. Neste caso, consideram-se três tipos de canais que, em função de formas diferentes de governança das transações, se subdividem em vários canais de comercialização. Deste modo, os canais de comercialização desdobram-se nas seguintes opções: o produtor exporta por meio de empresa própria que detém total ou parcialmente no país de destino, optando, deste modo, pela integração vertical dos canais de comercialização; o produtor exporta diretamente de Portugal para os distribuidores nos países de destino, sob diversas formas híbridas de governança (contratos de médio e longo prazos e contratos de curto prazo) ou sem contrato de coordenação em operações de mercado spot; o produtor procede à venda direta a um importador que toma a posse do produto, sob diversas formas híbridas de governança (contratos de médio e longo prazos e contratos de curto prazo) ou em operações de mercado spot.

O grupo características das transações conta com 13 variáveis que permitem avaliar as características das transações relativas ao processo de exportação utilizado pelas empresas, nomeadamente a especificidade dos ativos, a incerteza das transações e a frequência das transações.

A especificidade dos ativos foi medida por uma escala Likert de cinco níveis, levando em conta os seguintes aspectos relacionados à especificidade dos recursos humanos e à logística: se é difícil um novo agente aprender como as coisas são feitas; se um novo vendedor tem de despender muito tempo para conhecer os clientes e a especificidade do produto; se, em termos logísticos, é necessário despender recursos significativos para adaptar o produto às exigências do país de destino.

A incerteza das transações também foi avaliada por uma escala Likert de cinco níveis, considerando como fatores de incerteza a exigência dos compradores, ações dos concorrentes, o ambiente institucional dos países de destino e a quantidade de concorrentes. 
A frequência das transações foi avaliada em cada canal de comercialização em recorrente, ocasional ou nunca.

Por último, o grupo de questões relativo às perspectivas futuras, que inclui quatro variáveis que pretendem avaliar as expectativas futuras dos produtores no que diz respeito ao crescimento da empresa e das suas exportações.

\section{RESULTADOS}

Na Tabela 1, há a caracterização das empresas do setor do vinho no Alentejo em termos da produção, das vendas e do volume de negócios. A produção e as vendas de vinho médias por empresa são praticamente iguais e situam-se ligeiramente acima dos 24.000 hectolitros. Ambos os indicadores apresentam um desvio padrão elevado (praticamente 42.000 hectolitros), o que indica uma grande disparidade entre as empresas analisadas. A média do volume de negócios é de 4974 740,95 euros e o valor do desvio padrão também é bastante significativo.

Tabela 1. Caracterização das empresas: produção (hl),vendas (hl) e volume de negócios (€)

\begin{tabular}{cccc} 
Variáveis & N & Média & Desvio padrão \\
\hline Produção & 20 & $24,299.12$ & $42,721.20$ \\
Vendas & 20 & $24,382.25$ & $41,481.46$ \\
Volume de negócios & 20 & $4,974,740.95$ & $7,180,232.64$ \\
\hline
\end{tabular}

Fonte: elaboração própria.

Em 2016, 45\% das empresas tinham entre 10 a 50 funcionários permanentes, 30\% das empresas tinham entre 1 e 10 funcionários e $25 \%$ das empresas tinham mais de 50 funcionários. Esses dados, bem como o volume de negócios, parecem indicar que as empresas analisadas têm uma dimensão considerável. Em relação à forma de constituição das empresas, verifica-se que a estrutura empresarial é bastante diversificada. Ainda assim, $45 \%$ das empresas estão constituídas como sociedades por quotas, $20 \%$ são cooperativas e, representado as sociedades anônimas, 15\%. A maioria das empresas (80\%) encontra-se presente nos mercados internacionais, o que indica a importância que estes têm para o setor vitivinícola alentejano.

Todos os empresários inquiridos têm habilitações em nível de ensino superior, verificando-se que $60 \%$ possuem bacharelado/licenciatura, 30\%, pós-graduação/mestrado e $10 \%$, doutorado. Quanto à idade dos empresários, pode-se observar grande dispersão de idades, desde a faixa dos 26 a 35 anos até mais de 66 anos. No entanto, a faixa dos 46 a 55 anos é a que apresenta a percentagem mais elevada (30\%).

As exportações têm um valor bastante significativo no volume de negócios das empresas do setor do vinho no Alentejo. Para 50\% das empresas, o valor das exportações assume um peso entre $21 \%$ e $35 \%$ do volume de negócios total. Na Tabela 2, podemos observar o peso das exportações, tendo em conta o mercado de destino dos vinhos alentejanos (Europa, fora da Europa e África).

Para 43,75\% das empresas, a exportação para países europeus tem um peso entre $6 \%$ e $10 \%$ das exportações, e para $25 \%$ das empresas, esses mercados têm um peso entre $11 \%$ e $20 \%$ do total das exportações. Já para os países fora da Europa, exceto África, existe uma grande dispersão, sendo importante salientar que 6,25\% das empresas exportam essencialmente para esses mercados, uma vez que admitem um peso entre $51 \%$ e $65 \%$ do valor total das suas exportações. Já para o mercado africano, a exportação é mais residual quando comparado com os mercados anteriormente mencionados, uma vez que para $50 \%$ das empresas, o peso desses mercados no valor total das exportações é inferior a 5\%. A maior parte das exportações para esses mercados é de vinho engarrafado, já que $62,5 \%$ das empresas exportam o seu produto dessa forma mais de $65 \%$ das vezes, assumindo o bag-inbox e o vinho a granel valores residuais. 
Tabela 2. Peso das exportações por destino

\begin{tabular}{|c|c|c|c|c|c|}
\hline Variáveis & $\mathbf{N}$ & Grau & Frequência & Percentagem & $\begin{array}{l}\text { Percentagem } \\
\text { acumulada }\end{array}$ \\
\hline \multirow{7}{*}{$\begin{array}{c}\text { Exportação para países } \\
\text { europeus }\end{array}$} & \multirow{7}{*}{16} & Menos de $5 \%$ & 0 & $0.00 \%$ & $0.00 \%$ \\
\hline & & $6 \%$ a $10 \%$ & 7 & $43.75 \%$ & $43.75 \%$ \\
\hline & & $11 \%$ a $20 \%$ & 4 & $25.00 \%$ & $68.75 \%$ \\
\hline & & $21 \%$ a $35 \%$ & 3 & $18.75 \%$ & $87.50 \%$ \\
\hline & & $36 \%$ a $50 \%$ & 0 & $0.00 \%$ & $87.50 \%$ \\
\hline & & $51 \%$ a $65 \%$ & 1 & $6.25 \%$ & $93.75 \%$ \\
\hline & & Mais de $65 \%$ & 1 & $6.25 \%$ & $100.00 \%$ \\
\hline \multirow{6}{*}{$\begin{array}{c}\text { Exportação para países } \\
\text { fora da Europa (exceto } \\
\text { África) }\end{array}$} & \multirow{7}{*}{16} & Menos de $5 \%$ & 3 & $18.75 \%$ & $18.75 \%$ \\
\hline & & $6 \%$ a $10 \%$ & 3 & $18.75 \%$ & $37.50 \%$ \\
\hline & & $11 \%$ a $20 \%$ & 3 & $18.75 \%$ & $56.25 \%$ \\
\hline & & $21 \%$ a $35 \%$ & 3 & $18.75 \%$ & $75.00 \%$ \\
\hline & & $36 \%$ a $50 \%$ & 3 & $18.75 \%$ & $93.75 \%$ \\
\hline & & $51 \%$ a $65 \%$ & 1 & $6.25 \%$ & $100.00 \%$ \\
\hline \multirow{8}{*}{$\begin{array}{c}\text { Exportação para países } \\
\text { africanos }\end{array}$} & & Mais de $65 \%$ & 0 & $0.00 \%$ & $100.00 \%$ \\
\hline & \multirow{7}{*}{16} & Menos de $5 \%$ & 8 & $50.00 \%$ & $50.00 \%$ \\
\hline & & $6 \%$ a $10 \%$ & 2 & $12.50 \%$ & $62.50 \%$ \\
\hline & & $11 \%$ a $20 \%$ & 3 & $18.75 \%$ & $81.25 \%$ \\
\hline & & $21 \%$ a $35 \%$ & 1 & $6.25 \%$ & $87.50 \%$ \\
\hline & & $36 \%$ a $50 \%$ & 0 & $0.00 \%$ & $87.50 \%$ \\
\hline & & $51 \%$ a $65 \%$ & 2 & $12.50 \%$ & $100.00 \%$ \\
\hline & & Mais de $65 \%$ & 0 & $0.00 \%$ & $100.00 \%$ \\
\hline
\end{tabular}

Fonte: elaboração própria.

Um dos objetivos deste trabalho consiste em identificar os canais de comercialização de exportação utilizados pelas empresas do setor do vinho no Alentejo, bem como a forma como se relacionam os agentes nos canais de comercialização. A maioria das empresas utiliza vários canais de distribuição para proceder à exportação dos seus vinhos. O canal venda a um importador que toma posse dos produtos é o mais utilizado, sendo utilizado por $37,5 \%$ das empresas, e representa entre $81 \%$ e $100 \%$ do valor das exportações. O canal de exportação diretamente de Portugal para os distribuidores do país de destino tem um peso significativo, dado que para $31,25 \%$ das empresas, representa $81 \%$ a $100 \%$ do valor das transações com o exterior. O elevado peso do canal da venda a importadores que tomam a posse do produto em uma percentagem relativamente elevada de empresas poderá indiciar um nível relativamente reduzido de integração dos canais de exportação das empresas do vinho no Alentejo.

$\mathrm{Na}$ Tabela 3, podemos observar a representatividade dos vários canais de comercialização, tendo em conta o tipo de arranjo institucional ou o contrato utilizado.

A maioria das empresas não utiliza contratos ao realizar transações ou apenas contratos de transferência da posse do produto. Portanto, a maioria das transações é feita isoladamente, não existindo nenhum contrato com os distribuidores/retalhistas dos países de destino nem com os importadores. No entanto, parece haver uma tendência a arranjos institucionais mais complexos nas situações em que há maior nível de integração dos canais e preferência pelo mercado à vista (spot) quando o nível de integração dos canais é menor. Por exemplo, 43,75\% das empresas exportam diretamente de Portugal para os distribuidores dos países de destino e coordenam suas transações por meio de contratos de médio e longo prazos. No caso do canal de comercialização da venda a um importador que toma a posse do produto, a percentagem de operações em mercado à vista representa também $62,5 \%$ do total, mas a percentagem de empresas que regulam as transações por meio de contratos de curto prazo e de contratos de médio e longo prazos é manifestamente inferior, cifrando-se em 12,5\% para ambos os casos. 
Tabela 3. Canais de exportação e tipos de contrato

\begin{tabular}{|c|c|c|c|c|c|c|}
\hline Canal de exportação & Tipo de contrato & $\mathbf{N}$ & Grau & Frequência & Percentagem & $\begin{array}{l}\text { Percentagem } \\
\text { acumulada }\end{array}$ \\
\hline \multirow{6}{*}{$\begin{array}{c}\text { Exportação } \\
\text { diretamente de } \\
\text { Portugal }\end{array}$} & \multirow{6}{*}{$\begin{array}{c}\text { Médio a longo } \\
\text { prazo }\end{array}$} & \multirow{6}{*}{16} & $1 \%$ a $20 \%$ & 0 & $0.00 \%$ & $0.00 \%$ \\
\hline & & & $21 \%$ a $40 \%$ & 1 & $6.25 \%$ & $6.25 \%$ \\
\hline & & & $41 \%$ a $60 \%$ & 2 & $12.50 \%$ & $18.75 \%$ \\
\hline & & & $61 \%$ a $80 \%$ & 1 & $6.25 \%$ & $25.00 \%$ \\
\hline & & & $81 \%$ a $100 \%$ & 3 & $18.75 \%$ & $43.75 \%$ \\
\hline & & & Não se aplica & 9 & $56.25 \%$ & $100.00 \%$ \\
\hline \multirow{6}{*}{$\begin{array}{c}\text { Exportação } \\
\text { diretamente de } \\
\text { Portugal }\end{array}$} & \multirow{6}{*}{ Curto prazo } & \multirow{6}{*}{16} & $1 \%$ a $20 \%$ & 4 & $25.00 \%$ & $25.00 \%$ \\
\hline & & & $21 \%$ a $40 \%$ & 1 & $6.25 \%$ & $31.25 \%$ \\
\hline & & & $41 \%$ a $60 \%$ & 0 & $0.00 \%$ & $31.25 \%$ \\
\hline & & & $61 \%$ a $80 \%$ & 0 & $0.00 \%$ & $31.25 \%$ \\
\hline & & & $81 \%$ a $100 \%$ & 0 & $0.00 \%$ & $31.25 \%$ \\
\hline & & & Não se aplica & 11 & $68.75 \%$ & $100.00 \%$ \\
\hline \multirow{6}{*}{$\begin{array}{c}\text { Exportação } \\
\text { diretamente de } \\
\text { Portugal }\end{array}$} & \multirow{6}{*}{ Sem contrato } & \multirow{6}{*}{16} & $1 \%$ a $20 \%$ & 3 & $18.75 \%$ & $18.75 \%$ \\
\hline & & & $21 \%$ a $40 \%$ & 1 & $6.25 \%$ & $25.00 \%$ \\
\hline & & & $41 \%$ a $60 \%$ & 0 & $0.00 \%$ & $25.00 \%$ \\
\hline & & & $61 \%$ a $80 \%$ & 0 & $0.00 \%$ & $25.00 \%$ \\
\hline & & & $81 \%$ a $100 \%$ & 6 & $37.50 \%$ & $62.50 \%$ \\
\hline & & & Não se aplica & 6 & $37.50 \%$ & $100.00 \%$ \\
\hline \multirow{6}{*}{$\begin{array}{l}\text { Venda a um } \\
\text { importador }\end{array}$} & \multirow{6}{*}{$\begin{array}{c}\text { Médio a longo } \\
\text { prazo }\end{array}$} & \multirow{6}{*}{16} & $1 \%$ a $20 \%$ & 1 & $6.25 \%$ & $6.25 \%$ \\
\hline & & & $21 \%$ a $40 \%$ & 0 & $0.00 \%$ & $6.25 \%$ \\
\hline & & & $41 \%$ a $60 \%$ & 0 & $0.00 \%$ & $6.25 \%$ \\
\hline & & & $61 \%$ a $80 \%$ & 1 & $6.25 \%$ & $12.50 \%$ \\
\hline & & & $81 \%$ a $100 \%$ & 2 & $12.50 \%$ & $25.00 \%$ \\
\hline & & & Não se aplica & 12 & $75.00 \%$ & $100.00 \%$ \\
\hline \multirow{6}{*}{$\begin{array}{l}\text { Venda a um } \\
\text { importador }\end{array}$} & \multirow{6}{*}{ Curto prazo } & \multirow{6}{*}{16} & $1 \%$ a $20 \%$ & 2 & $12.50 \%$ & $12.50 \%$ \\
\hline & & & $21 \%$ a $40 \%$ & 0 & $0.00 \%$ & $12.50 \%$ \\
\hline & & & $41 \%$ a $60 \%$ & 0 & $0.00 \%$ & $12.50 \%$ \\
\hline & & & $61 \%$ a $80 \%$ & 0 & $0.00 \%$ & $12.50 \%$ \\
\hline & & & $81 \%$ a $100 \%$ & 0 & $0.00 \%$ & $12.50 \%$ \\
\hline & & & Não se aplica & 14 & $87.50 \%$ & $100.00 \%$ \\
\hline \multirow{6}{*}{$\begin{array}{l}\text { Venda a um } \\
\text { importador }\end{array}$} & \multirow{6}{*}{ Sem contrato } & \multirow{6}{*}{16} & $1 \%$ a $20 \%$ & 1 & $6.25 \%$ & $6.25 \%$ \\
\hline & & & $21 \%$ a $40 \%$ & 0 & $0.00 \%$ & $6.25 \%$ \\
\hline & & & $41 \%$ a $60 \%$ & 0 & $0.00 \%$ & $6.25 \%$ \\
\hline & & & $61 \%$ a $80 \%$ & 0 & $0.00 \%$ & $6.25 \%$ \\
\hline & & & $81 \%$ a $100 \%$ & 9 & $56.25 \%$ & $62.50 \%$ \\
\hline & & & Não se aplica & 6 & $37.50 \%$ & $100.00 \%$ \\
\hline
\end{tabular}

Fonte: elaboração própria.

Na Tabela 4, constam os resultados das variáveis utilizadas para estudar a incerteza das transações.

No âmbito do setor vitivinícola, a incerteza assume um papel bastante importante no aumento dos custos de transação. As exigências dos compradores (por exemplo, de packaging), o ambiente institucional dos países de destino e o elevado número de concorrentes são os principais fatores de incerteza nas transações, já que foram referidos por mais de dois terços das empresas analisadas. 
Tabela 4. Incerteza nos canais de comercialização

\begin{tabular}{|c|c|c|c|c|c|}
\hline Variáveis & $\mathbf{N}$ & Grau & Frequência & Percentagem & $\begin{array}{l}\text { Percentagem } \\
\text { acumulada }\end{array}$ \\
\hline \multirow{7}{*}{$\begin{array}{l}\text { Exigência dos } \\
\text { compradores }\end{array}$} & \multirow{7}{*}{16} & Discordo totalmente & 0 & $0.00 \%$ & $0.00 \%$ \\
\hline & & Discordo muito & 0 & $0.00 \%$ & $0.00 \%$ \\
\hline & & Discordo & 2 & $12.50 \%$ & $12.50 \%$ \\
\hline & & Nem concordo nem discordo & 5 & $31.25 \%$ & $43.75 \%$ \\
\hline & & Concordo & 6 & $37.50 \%$ & $81.25 \%$ \\
\hline & & Concordo muito & 2 & $12.50 \%$ & $93.75 \%$ \\
\hline & & Concordo totalmente & 1 & $6.25 \%$ & $100.00 \%$ \\
\hline \multirow{7}{*}{$\begin{array}{c}\text { Ações dos } \\
\text { concorrentes }\end{array}$} & \multirow{7}{*}{16} & Discordo totalmente & 0 & $0.00 \%$ & $0.00 \%$ \\
\hline & & Discordo muito & 0 & $0.00 \%$ & $0.00 \%$ \\
\hline & & Discordo & 6 & $37.50 \%$ & $37.50 \%$ \\
\hline & & Nem concordo nem discordo & 5 & $31.25 \%$ & $68.75 \%$ \\
\hline & & Concordo & 2 & $12.50 \%$ & $81.25 \%$ \\
\hline & & Concordo muito & 1 & $6.25 \%$ & $87.50 \%$ \\
\hline & & Concordo totalmente & 2 & $12.50 \%$ & $100.00 \%$ \\
\hline \multirow{7}{*}{$\begin{array}{c}\text { Ambiente } \\
\text { institucional } \\
\text { dos países }\end{array}$} & \multirow{7}{*}{16} & Discordo totalmente & 0 & $0.00 \%$ & $0.00 \%$ \\
\hline & & Discordo muito & 0 & $0.00 \%$ & $0.00 \%$ \\
\hline & & Discordo & 2 & $12.50 \%$ & $12.50 \%$ \\
\hline & & Nem concordo nem discordo & 3 & $18.75 \%$ & $31.25 \%$ \\
\hline & & Concordo & 5 & $31.25 \%$ & $62.50 \%$ \\
\hline & & Concordo muito & 4 & $25.00 \%$ & $87.50 \%$ \\
\hline & & Concordo totalmente & 2 & $12.50 \%$ & $100.00 \%$ \\
\hline \multirow{7}{*}{$\begin{array}{l}\text { Quantidade } \\
\text { de } \\
\text { concorrentes }\end{array}$} & \multirow{7}{*}{16} & Discordo totalmente & 0 & $0.00 \%$ & $0.00 \%$ \\
\hline & & Discordo muito & 0 & $0.00 \%$ & $0.00 \%$ \\
\hline & & Discordo & 0 & $0.00 \%$ & $0.00 \%$ \\
\hline & & Nem concordo nem discordo & 2 & $12.50 \%$ & $12.50 \%$ \\
\hline & & Concordo & 4 & $25.00 \%$ & $37.50 \%$ \\
\hline & & Concordo muito & 4 & $25.00 \%$ & $62.50 \%$ \\
\hline & & Concordo totalmente & 6 & $37.50 \%$ & $100.00 \%$ \\
\hline
\end{tabular}

Fonte: elaboração própria.

Neste estudo foram considerados dois tipos de ativos específicos, sendo eles os relativos aos recursos humanos e a questões logísticas, mais concretamente os recursos que uma empresa necessita despender para adaptar o produto às exigências dos mercados de destino. $\mathrm{Na}$ Tabela 5, são apresentados os resultados da análise efetuada para a especificidade dos ativos.

Os ativos relacionados com os recursos humanos são bastante específicos, uma vez que tanto os mercados como o produto em estudo são bastante complexos. Observa-se que $50 \%$ das empresas concordam que não é fácil para um novo agente aprender todas as questões relativas ao funcionamento dos canais. A maioria das empresas concorda que para um vendedor ser eficaz precisa de muito tempo para conhecer os clientes e conhecer 
minuciosamente os produtos, o que é perfeitamente previsível, pois o vinho é um produto com características intrínsecas bastante complexas. O mercado de vinhos é bastante competitivo e possui características únicas. Por isso, um novo agente poderá ter alguma dificuldade em operar imediatamente de forma eficiente, o que poderá criar relações de dependência entre os agentes.

Tabela 5. Especificidade dos ativos nos canais de comercialização

\begin{tabular}{|c|c|c|c|c|c|}
\hline Variáveis & $\mathbf{N}$ & Grau & Frequência & Percentagem & $\begin{array}{c}\text { Percentagem } \\
\text { acumulada }\end{array}$ \\
\hline \multirow{7}{*}{$\begin{array}{l}\text { Dificuldade para } \\
\text { novos agentes } \\
\text { aprenderem a } \\
\text { operar no canal }\end{array}$} & \multirow{7}{*}{16} & Discordo totalmente & 0 & $0.00 \%$ & $0.00 \%$ \\
\hline & & Discordo muito & 3 & $18.75 \%$ & $18.75 \%$ \\
\hline & & Discordo & 2 & $12.50 \%$ & $31.25 \%$ \\
\hline & & Nem concordo nem discordo & 3 & $18.75 \%$ & $50.00 \%$ \\
\hline & & Concordo & 5 & $31.25 \%$ & $81.25 \%$ \\
\hline & & Concordo muito & 1 & $6.25 \%$ & $87.50 \%$ \\
\hline & & Concordo totalmente & 2 & $12.50 \%$ & $100.00 \%$ \\
\hline \multirow{6}{*}{$\begin{array}{l}\text { Para ser eficaz, } \\
\text { um vendedor } \\
\text { precisa } \\
\text { despender } \\
\text { muito tempo } \\
\text { para conhecer } \\
\text { os clientes }\end{array}$} & \multirow{7}{*}{16} & Discordo totalmente & 0 & $0.00 \%$ & $0.00 \%$ \\
\hline & & Discordo muito & 0 & $0.00 \%$ & $0.00 \%$ \\
\hline & & Discordo & 1 & $6.25 \%$ & $6.25 \%$ \\
\hline & & Nem concordo nem discordo & 0 & $0.00 \%$ & $6.25 \%$ \\
\hline & & Concordo & 4 & $25.00 \%$ & $31.25 \%$ \\
\hline & & Concordo muito & 5 & $31.25 \%$ & $62.50 \%$ \\
\hline \multirow{8}{*}{$\begin{array}{l}\text { Leva muito } \\
\text { tempo até um } \\
\text { vendedor } \\
\text { conhecer } \\
\text { minuciosamente } \\
\text { os produtos }\end{array}$} & & Concordo totalmente & 6 & $37.50 \%$ & $100.00 \%$ \\
\hline & \multirow{7}{*}{16} & Discordo totalmente & 0 & $0.00 \%$ & $0.00 \%$ \\
\hline & & Discordo muito & 1 & $6.25 \%$ & $6.25 \%$ \\
\hline & & Discordo & 1 & $6.25 \%$ & $12.50 \%$ \\
\hline & & Nem concordo nem discordo & 2 & $12.50 \%$ & $25.00 \%$ \\
\hline & & Concordo & 9 & $56.25 \%$ & $81.25 \%$ \\
\hline & & Concordo muito & 1 & $6.25 \%$ & $87.50 \%$ \\
\hline & & Concordo totalmente & 2 & $12.50 \%$ & $100.00 \%$ \\
\hline \multirow{7}{*}{$\begin{array}{l}\text { Em termos } \\
\text { logísticos, são } \\
\text { necessários } \\
\text { recursos } \\
\text { significativos } \\
\text { para adaptar o } \\
\text { produto à } \\
\text { exigência dos } \\
\text { mercados de } \\
\text { destino }\end{array}$} & \multirow{7}{*}{16} & Discordo totalmente & 0 & $0.00 \%$ & $0.00 \%$ \\
\hline & & Discordo muito & 0 & $0.00 \%$ & $0.00 \%$ \\
\hline & & Discordo & 2 & $12.50 \%$ & $12.50 \%$ \\
\hline & & Nem concordo nem discordo & 4 & $25.00 \%$ & $37.50 \%$ \\
\hline & & Concordo & 4 & $25.00 \%$ & $62.50 \%$ \\
\hline & & Concordo muito & 3 & $18.75 \%$ & $81.25 \%$ \\
\hline & & Concordo totalmente & 3 & $18.75 \%$ & $100.00 \%$ \\
\hline
\end{tabular}

Fonte: elaboração própria.

Em relação às questões logísticas, a especificidade dos ativos também é elevada, dado que a maioria das empresas concorda serem necessários recursos significativos para adaptar o produto às exigências dos mercados nos países de destino. 
Na Tabela 6, constam os dados relativos à frequência das transações. Para as empresas que possuem uma empresa importadora no país de destino, apenas $12,5 \%$ têm transações recorrentes com o mesmo agente. Aproximadamente um terço das empresas que usam o canal de exportação diretamente de Portugal para os distribuidores/retalhistas com contratos de curto prazo realiza transações recorrentes com o mesmo agente. Para esse tipo de canal, mas utilizando contratos de médio/longo prazos, a percentagem de empresas que realiza transações recorrentes é mais elevada $(43,75 \%)$. Já no canal de venda a um importador que toma posse do produto, a porcentagem de empresas que realizam transações ocasionalmente e que nunca repetem transações com o mesmo agente é superior à das que realizam transações de forma recorrente. Esses resultados sugerem que quando existem contratos de médio/ longo prazos, as transações com o mesmo agente tendem a ser mais frequentes.

Tabela 6. Frequência das transações nos canais de comercialização

\begin{tabular}{|c|c|c|c|c|c|}
\hline Variáveis & $\mathbf{N}$ & Grau & Frequência & Percentagem & $\begin{array}{l}\text { Percentagem } \\
\text { acumulada }\end{array}$ \\
\hline \multirow{3}{*}{$\begin{array}{l}\text { Empresa importadora } \\
\text { própria no país de destino }\end{array}$} & \multirow{3}{*}{16} & Recorrente & 2 & $12.50 \%$ & $12.50 \%$ \\
\hline & & Ocasional & 1 & $6.25 \%$ & $18.75 \%$ \\
\hline & & Nunca & 13 & $81.25 \%$ & $100.00 \%$ \\
\hline \multirow{3}{*}{$\begin{array}{c}\text { Exportação diretamente de } \\
\text { Portugal (contratos de } \\
\text { curto prazo) }\end{array}$} & \multirow{3}{*}{16} & Recorrente & 5 & $31.25 \%$ & $31.25 \%$ \\
\hline & & Ocasional & 5 & $31.25 \%$ & $62.50 \%$ \\
\hline & & Nunca & 6 & $37.50 \%$ & $100.00 \%$ \\
\hline \multirow{4}{*}{$\begin{array}{l}\text { Exportação diretamente de } \\
\text { Portugal (contratos de } \\
\text { médio/ longo prazos) }\end{array}$} & \multirow{3}{*}{16} & Recorrente & 7 & $43.75 \%$ & $43.75 \%$ \\
\hline & & Ocasional & 3 & $18.75 \%$ & $62.50 \%$ \\
\hline & & Nunca & 6 & $37.50 \%$ & $100.00 \%$ \\
\hline & \multirow{3}{*}{16} & Recorrente & 3 & $18.75 \%$ & $18.75 \%$ \\
\hline \multirow[t]{2}{*}{$\begin{array}{l}\text { Venda a um importador } \\
\text { (contratos de curto prazo) }\end{array}$} & & Ocasional & 4 & $25.00 \%$ & $43.75 \%$ \\
\hline & & Nunca & 9 & $56.25 \%$ & $100.00 \%$ \\
\hline \multirow{3}{*}{$\begin{array}{c}\text { Venda a um importador } \\
\text { (contratos de médio/longo } \\
\text { prazos) }\end{array}$} & \multirow{3}{*}{16} & Recorrente & 4 & $25.00 \%$ & $25.00 \%$ \\
\hline & & Ocasional & 5 & $31.25 \%$ & $56.25 \%$ \\
\hline & & Nunca & 7 & $43.75 \%$ & $100.00 \%$ \\
\hline
\end{tabular}

Fonte: elaboração própria.

É ainda interessante perceber a forma como as empresas vitivinícolas do Alentejo preveem o futuro nos mercados externos. É consensual entre as empresas analisadas a vontade de aumentar o valor das exportações para novos mercados, bem como intensificar as exportações para os mercados onde já se encontram presentes. A maior parte (75\%) das empresas acredita que as vendas aumentarão em razão das exportações e cerca de $40 \%$ preveem a contratação de novos funcionários. Portanto, os empresários do setor do vinho no Alentejo mantêm percepções positivas em relação às exportações.

Os resultados obtidos enquadraram-se nas intuições teóricas de Crawford \& Ostrom (1995). No entanto, contrastam em alguns pontos com os resultados obtidos por outros autores, nomeadamente $o$ fato de a integração vertical ser geralmente a forma de organização preferida dos produtores e nas regiões emergentes na produção de vinho (Miranda, 2016). 


\section{CONCLUSÃO}

Este estudo pretendeu caracterizar a estrutura dos canais de comercialização de exportação das empresas vitivinícolas do Alentejo, tendo como objetivo determinar o seu nível de integração e compreender as principais razões que o determinam. Os dados foram recolhidos por meio de um questionário aplicado a uma amostra de produtores de vinhos inscritos na base de dados da CVRA.

Os resultados obtidos permitem concluir que as empresas do setor do vinho no Alentejo utilizam vários canais de comercialização para exportar seus produtos. A venda a importadores no país de destino que tomam posse da produção e a venda diretamente de Portugal aos distribuidores e varejistas nos países de destino são os canais de comercialização mais utilizados. O relacionamento com os agentes dos canais é feito principalmente em transações isoladas em um regime de mercado à vista (spot), não existindo contrariamente ao que se previa, uma verdadeira coordenação dos canais por meio de contratos a médio e longo prazos ou de contratos a curto prazo.

O grau de incerteza das transações tem influência nos custos de transação e na escolha dos arranjos institucionais. O elevado número de concorrentes nos mercados externos é uma das principais fontes de incerteza. Outra fonte importante de incerteza são as exigências feitas pelos compradores, como um determinado packaging que não estava inicialmente previsto e que aumentará os custos da transação. Os ambientes institucionais dos países de destino afetam a incerteza das transações.

Os recursos humanos e questões de logística relacionadas à adaptação dos produtos aos países de destino são os ativos específicos que mais determinam os custos de transação, dado que é necessário bastante tempo para formar os recursos humanos e as características do setor; nomeadamente, os fatores imateriais constituem também ativos específicos importantes, o que poderá levar a relações de dependência.

A frequência das transações é mais elevada quando existem graus de integração dos canais mais elevados, já que as transações são mais recorrentes quando são coordenadas por meio de contratos de médio e longo prazos.

Em termos de perspectivas futuras, os empresários acreditam que as exportações são uma das variáveis que mais farão aumentar as vendas. Por isso, pretendem aumentar a exportação para novos mercados e intensificá-la para os mercados atuais.

Em termos gerais, os resultados do estudo permitem concluir que o nível de integração dos canais de comercialização de exportação utilizados pelas empresas do setor do vinho no Alentejo é ainda relativamente reduzido. Independentemente do canal utilizado, as transações realizam-se, em sua maior parte, de forma isolada, em regime de mercado vista (spot). Tendo em conta as características das transações, nomeadamente a elevada especificidade dos ativos imateriais e de logística, a incerteza e a frequência das transações, preveem-se custos de transação relativamente elevados nas operações de exportação. A adoção de formas de coordenação dos canais mais integradas, como contratos de médio e longo prazos, poderia contribuir para reduzir substancialmente os custos de transação e tornar os processos de exportação das empresas do setor do vinho no Alentejo mais eficientes.

\section{REFERÊNCIAS}

Akerlof, G. (1970). The Market for "Lemons": Quality uncertainty and the market mechanism. The Quarterly Journal of Economics, 84(3), 488-500.

Crawford, S. E. S., \& Ostrom, E. (1995). A grammar of institutions. The American Political Science Review, $89(3), 582-600$.

Christy, D., \& Grout, J. (1994). Safeguarding supply chain relationships. International Journal of Production Economics, 36(3), 233-242.

Coase, R. (1937). The nature of the firm. London: Economics, New Series.

Corey, R., Céspedes, F., \& Rang, V. (1989). Going to market: distribution systems for industrial products. Boston, MA: Harvard Business School Press. 
Codron, J., Montaigne, E., \& Rousset, S. (2013). Quality management and contractual incompleteness: Grape procurement for high-end wines in Argentina. Journal on Chain and Network Science, 13(1), 11-35.

Fernández-Olmos, M., Rosell-Martínez, J., \& Espitia-Escuer, M. (2009). Vertical Integration in the Wine Industry: A transaction costs analysis on the Rioja DOCa. Agribusiness, 25(2), 231-250.

Fernández-Olmos, M. (2010). The performance implications of 'Grow or Buy' decisions in the wine industry. Food Policy, 35(3), 256-264.

Fragoso, R. (2013). Planning marketing channels: case of the olive oil agribusiness in Portugal. Journal of Agricultural \& Food Industrial Organization, 11(1), 1-17.

Fraser, I. (2005). Microeconometric Analysis of Wine Grape Supply Contracts in Australia. The Australian Journal of Agricultural and Resource Economics, 49(1), 23-46.

Instituto Nacional de Estatística (2016). Estatísticas do Comércio Internacional. Lisboa: INE.

Instituto da Vinha e do Vinho (2015). Anuário de Vinhos e Aguardentes - Portugal 2015. Anuário - Vinhos e Aguardentes de Portugal. Retrieved in 2017, January 15, from www.ivv.min-agricultura.pt.

Jap, S., \& Anderson, E. (2003). Safeguarding Interorganizational Performance and Continuity under Ex Post Opportunism. Management Science, 49(12), 1684-1701.

Kabadayi, S. (2011). Choosing the right multiple channel system to minimize transaction costs. Industrial Marketing Management, 40, 763-773.

Klein, S., Frazier, G., \& Roth, V. (1990). A transaction cost analysis model of channel integration in international markets. JMR, Journal of Marketing Research, 27(2), 196-208.

Kumar, N., Scheer, L., \& Steenkamp, J. (1995). The effects of perceived independence on dealer attitudes. JMR, Journal of Marketing Research, 32, 348-356.

Lopes, M. (2009). Análise dos canais de distribuição do etanol carburante brasileiro: um estudo exploratório (Tese de mestrado). Engenharia da Produção, Universidade Federal de São Carlos, São Carlos.

Miranda, B. V. (2016). Organizational diversity in U.S. emerging wine regions (PhD thesis). University of Missouri, Columbia.

Neves, M. (1990). Um modelo para planejamento de canais de distribuição no setor de alimentos (Tese de Doutorado). Faculdade de Economia, Administração e Contabilidade, Universidade de São Paulo, São Paulo.

Pelton, L., Strutton, D., \& Lumpkin, J. (1997). Marketing Channels: A relationship management approach. Boston: McGraw-Hill.

Peterson, H., Wysocki, A., \& Harsh, S. (2001). Strategic choice along the vertical coordination continuum. International Food and Agribusiness Management, 4, 149-166.

Rehme, J., Nordigarden, D., Ellestrom, D., \& Chicksand, D. (2016). Power in distribution channels Supplier assortment strategy for balancing power. Industrial Marketing Management, 54, 176-187.

Rosembloon, B. (1999). Marketing channels (6a ed.). Chicago: The Dryden Press.

Seggie, S. (2012). Transaction cost economics in international marketing: a review and suggestions for the future. Journal of International Marketing, 20, 49-71.

Shervani, T., Frazier, G., \& Challagalla, G. (2007). The moderating influence of firm market power on the transaction cost economics model: an empirical test in a forward channel integration context. Strategic Management Journal, 26, 635-652.

Stern, L., \& El-Ansary, A. (1988). Marketing channels (3ª ed.). Englewood Cliffs, NJ: Prentice-Hall, Inc.

Traversac, J., Rousset, S., \& Cornet, P. (2011). Farm resources, transaction costs and forward integration in agriculture: evidence from french wine producers. Food Policy, 36(6), 839-847.

Williamson, O. (1975). Markets and Hierarchies: Analysis and antitrust implications. New York: The Free Press.

Williamson, O. (1981). The Economics of Organization: The Transaction Cost Approach. American Journal of Sociology, 87(3), 548-577.

Williamson, O. (1985). The economic institutions of capitalism. ( $1^{\text {a }}$ ed.). New York: The Free Press.

Submetido em: 18/Out/2019

Aceito em: 19/Maio/2020

Classificação JEL: Q13 


\section{Material Suplementar}

Este artigo acompanha material suplementar.

Anexo - Questionário

Este material está disponível como parte da versão online do artigo na página: http://www.scielo.br/resr 